Research Article

\title{
Evolutionary Game Models on Multiagent Collaborative Mechanism in Responsible Innovation
}

\author{
Kun Yang, Wan Wang $(D$, and Bin Hu \\ School of Management Studies, Shanghai University of Engineering Science, Shanghai 201620, China \\ Correspondence should be addressed to Wan Wang; m030218140@sues.edu.cn
}

Received 11 May 2020; Revised 29 May 2020; Accepted 9 June 2020; Published 1 August 2020

Academic Editor: Lu Zhen

Copyright (c) 2020 Kun Yang et al. This is an open access article distributed under the Creative Commons Attribution License, which permits unrestricted use, distribution, and reproduction in any medium, provided the original work is properly cited.

\begin{abstract}
Innovation is a game process; in particular, the behavior among multiple agents in responsible innovation is susceptible to the influence of benefits, risks, responsibilities, and other factors, resulting in unstable collaborative relationships. Therefore, this paper constructs a tripartite evolutionary game model including the government, enterprises, and the public, combined with system dynamics modeling to simulate and analyze the tripartite behavior strategy and sensitivity to relevant exogenous variables. The study shows that the tripartite game eventually converges to a stable state of the government active supervision, enterprises making responsible innovation, and the public's positive participation. The positive participation of the public drives rapidly the game to a steady state, while the behavioral strategies of enterprises are more susceptible to the behavior of the government. Supervision cost, penalty amount, and value compensation are the most critical factors influencing the change of the corresponding agents' behavior strategy, and the final strategic stability of tripartite is affected by multiple exogenous variables.
\end{abstract}

\section{Introduction}

The world is facing enormous societal challenges such as climate change, food safety, society security, energy demand, demographic change, and well-being. These enormous challenges transcend national borders and have an impact on a large number of people, cities, and the entire planet [1]. Therefore, governments around the world are emphasizing the importance of innovation, because innovation and technological development are generally regarded as a panacea for grand societal challenges [2]. However, innovation is generally considered to be inherently good, but always has the probability of having unforeseen consequences [3]. In the short term, innovation may have certain advantages, but from a long-term perspective, innovation will face questions, dilemmas, and uncertainties in its future development. Today, many researchers agree that even the most promising innovations can fail because the ethical and societal concerns they bring are not properly taken into account [4]. In this context, Responsible Research and Innovation (RRI) is seen as a way of governance innovation development to address challenges such as population ageing, poverty, inequality, and the availability of highquality healthcare services $[5,6]$. RRI is a recent expression used by the European Union to indicate the part of its research and innovation (R\&I) strategy and is highly concerned by the realm of politics and academia, aiming to make the process and results of R\&I ethically acceptable and socially desirable [7]. RRI can add new elements to innovation governance by making R\&I participants jointly responsible for societal embedding and potential impact [8].

RRI is usually implemented from the perspective of policy or social ethics and focuses on the academic research and development environment [6], while responsible innovation (RI) pays more attention to the innovation process itself and has become a concept close to RRI [9]. For the research purpose of this paper, this research will use the term of RI. RI research revolves around whether and how to lead technology and innovation to socially desired goals [10] and manage innovation through early "upstream" interventions rather than post-event "downstream" monitoring and "corrective" interventions [11]. Its core is the process of open research and innovation, which incorporates "new voices of science and innovation governance" [12]; on the one hand, it 
aims to improve the legalization and democratization of the innovation process and output, and on the other hand, it attempts to increase the diversity of views to meet the needs of social actors [13]. To meet these needs, RI focuses on the participation and collaboration of stakeholders [14]; they need to continue to participate, not only in consultation, but also to provide information, power, and opportunities to play a role in decision-making to achieve what is called "mutually beneficial interaction" [13]. Meanwhile, this inclusiveness of upstream stakeholders and the public can help achieve collective responsibility to control and guide innovation so that it is ethically acceptable, societally desirable, and sustainable $[15,16]$. However, the current view of innovation in the RI literature tends to be narrow [9], and the research of RI should more adequately consider that innovation is an endogenous process resulting from the collaborative actions of interdependent heterogeneous agents in a complex system, where the outcomes are characterized by essential uncertainty $[17,18]$. At the same time, implementing RI in the business context also faces a series of important challenges. For example, first of all, focusing solely on science and technological development without considering other types of innovation can produce a narrow view on innovation [9]. Second, enterprises prioritize the economic impact achieved by innovation and focus more on commercially driven innovation processes [16]. Third, different stakeholders have various values and interests in the business context, and innovators face different constraints in terms of confidentiality and public image [4]. Furthermore, innovation is a process of the multiagent game [19]; when different stakeholders collaboratively engage in RI, the rationality of each agent is constrained by the limitations of available information, cognition, and decision-making time, which makes the collaborative relationship between multiple agents into a long-term dynamic game relationship where each agent continuously changes its strategy through imitation and learning to maximize its own benefits.

The abovementioned analysis can lead to the following questions:

How to establish a tripartite evolutionary game model for multiagent collaboration in RI?

How does the behavior of multiagent interact with each other in RI?

How to make effective collaboration mechanisms to promote multiagent cooperation and responsible innovation governance?

This paper first constructs a tripartite evolutionary game and analyzes the stability of each player's game strategy in the model. Then, a tripartite game system dynamics (SD) model is established by introducing SD, and their interaction relationship is studied by using simulation. Through theoretical analysis and extensive simulation, it is hoped that the three questions posed above can be answered.

This paper is organized as follows. Section 2 presents a literature review on the multiagent in RI and the tripartite evolutionary game. Section 3 develops the tripartite evolutionary game model and analyzes the equilibrium point and multiagent asymptotic stability. Section 4 advances numerical simulation analysis based on SD to illustrate the interaction relationship. Finally, conclusions and limitations are given in Section 5 .

\section{Literature Review}

2.1. Multiagent in Responsible Innovation. RI is a new concept developed and introduced by researchers and policymakers in a top-down manner [20]. The main idea behind it is to democratize innovation [21], and to implement collaborative governance forms such as stakeholder and public participation. Incorporating different stakeholders and the public into RI, in turn, means increasing the possibilities of anticipating and discerning how research and innovation may benefit society and prevent any negative consequences from occurring [22]. This can increase the chance of innovation being adopted, better embed innovation into society, and ensure that innovation brings societal benefits. Thus, first and foremost, it is important to identify the stakeholders in RI and classify these stakeholders.

RI is a means of emphasizing multistakeholder partnerships to mobilize and share knowledge, technology, and financial resources and to encourage and promote simultaneously effective public and civil society partnerships [6]. The main stakeholders are crucial to the innovation process, and there is a lot of literature discussing different stakeholders related to or participating in RI. Von Schomberg pointed out that the main stakeholders in RI include European citizen, consumer, producers, civil society, policymakers, etc., whose scope of action is mainly concentrated on the application phase of new technologies, the innovation process, and European legislation [23]. Davies and Horst summarize the most of stakeholders mentioned in the webbased and academic aspects related to RI, such as academic institutions, key users, researchers, businesses and supply chain organizations, funders and regulators, consumers, affected parties, and the society at large, etc. [24]. Silva classifies stakeholders in RI as internal stakeholders and external stakeholders, where external stakeholders include individual researchers, research organizations, civil society actors, legislators, public bodies, etc. [6]. Blok et al. put forward the classification according to economic and noneconomic stakeholders; for example, economic stakeholders have employees and suppliers, and noneconomic stakeholders have NGOs and research institutes [25]. Mei and Chen divide stakeholders into policymakers (e.g., governments and policy institutions at all levels), experts in innovation activities (e.g., business innovation planners, innovation implementation organizations or institutions), and society actors (e.g., the public, innovative social participants, and potential service targets) [26]. Therefore, given the research purpose of this paper and for the convenience of analysis, the stakeholders are classified according to the research of Mei and Chen [26], and the government, enterprises, and the public are selected as agents from the three categories. 
Innovation is a collaborative and game process of multiple parties. As a regulator, the government draws a legal red line that enterprises and their stakeholders cannot cross [27] and has the power to regulate innovation and influence the public's behavior [28]. The main purpose of enterprises is to pursue profits, and responsible activities of enterprise involvement will help it build a lasting positive image and good reputation [29]. Enterprises improve social outcomes by better coordinating with the government, the public, or other stakeholders and try to generate longlasting "win-win" solutions [30]. Participatory planning is a way of involving the public in the decision-making process, and public participation is an important aspect of democracy and trust in the government, which helps improve the legitimacy of decisions [31]. From the perspective of evolutionary economics, the public as a consumer plays a vital role in responsible innovation and demand [18]. On the one hand, they can actively exert pressure on enterprises to conduct innovation in a responsible manner; on the other hand, they are a significant reference group for enterprises to better align their products and services with consumers' expectations and needs [32]. The three main agents of the government, enterprise, and the public constitute the most important stakeholder group, and enterprises produce and sell products resulting from innovation, but innovation will not succeed without public acceptance, market diffusion, and government supervision of innovation development.

2.2. Tripartite Evolutionary Game. A key assumption of traditional game theory is that participants are completely rational, and this rationality assumption is not consistent with the facts [33]. Evolutionary game theory is a theory that combines game theory analysis and dynamic evolution process analysis, which overcomes the hypothesis of complete rationality and complete information in a game model [34]. At present, evolutionary game theory has been introduced into a wide range of fields, especially the tripartite evolutionary game, which is suitable for analyzing the cooperative game behavior of multiple stakeholders. Liu et al. establish a multiple agent's evolutionary game model that includes carbon fiber production enterprises, carbon fiber application enterprises, and governments and analyze the influencing factors of collaborative innovation in the carbon fiber industry to alleviate the problem of industry chain disconnection and promote sustainable development of the carbon fiber industry [35]. Guo and Li construct a tripartite evolutionary game model between the government, private sector, and owners and combine SD to simulate the evolution process, which can be helpful to explore the collaboration mechanism of participants in the PPP model of the old community renovation project [36]. Based on the mixed development environment of cascade hydropower stations, Chen et al. establish a tripartite evolutionary game model, which aims to explore the directions and conditions for cooperative and noncooperative strategies evolving into steady states and promote the joint operation of cascade hydropower stations [37].
However, the current research on multiagent collaboration in RI mainly focuses on qualitative analysis, such as the cooperation of stakeholders in the port RI model $[38,39]$, RI of stakeholders in small producers clusters [40], and RI and stakeholders collaboration in infrastructures [41]. The literature shows that few researchers incorporate the agent's bounded rationality into RI and study the collaborative problem of multiagent in RI through quantitative analysis, while the evolutionary game is suitable for analyzing behavior change of stakeholders. Thus, it would be more practical and meaningful to closely explore the collaboration mechanism in RI with boundedly rational agents based on a tripartite evolutionary game.

\section{Construction and Analysis of the Tripartite Evolutionary Game Model}

3.1. Model Assumptions. In this paper, the evolutionary game method is used to analyze the collaborative mechanism of multiagent under RI, so the following model assumptions are proposed. Meanwhile, for the convenience of analysis, this research will select the government, enterprises, and the public as three types of representatives among policymakers, innovation activity experts, and society actors.

Assume that each agent in the game model has two possible strategic choices. The government's strategic choices will be active supervision (AS) and inactive supervision (IS). The possible strategic choices for enterprises are to make responsible innovation (MRI) and irresponsible innovation (NMRI), respectively. The public's strategic choices will be positive participation (PP) and negative participation (NP). The probability of the government choosing AS is $x(0 \leq x \leq 1)$, the probability of enterprises choosing MRI is $y(0 \leq y \leq 1)$, and the probability of the public choosing $\mathrm{PP}$ is $z(0 \leq z \leq 1)$.

Assume that the relevant parameters related to the government are as follows. The government carries out active supervision and pays the supervision cost $C_{1}$, including investing a lot of human, material, and financial resources. RI meets social values and needs and brings social value income $R_{1}$ to the government. At the same time, the government will also provide financial assistance $M$ for enterprises that perform responsible innovation. However, when the government conducts passive supervision, the negative externalities of irresponsible innovation may bring about a social crisis and damage the reputation of the government, denoted by $B$.

Assume that the relevant parameters related to enterprises are as follows. The normal earnings on innovation for an enterprise are $R_{2}$, whereas RI increases R\&D investment $C_{2}$. However, the enterprises' irresponsible innovation may affect ethical, ecological, and sustainable development and bring potential risks $(D)$ to the public, and enterprises also are punished $(T)$ by the government. At the same time, in order to show a responsible attitude, the government of negative supervision will design policies in advance to require enterprises to compensate the amount $K_{1}$ for damages to the public at potential risk. 
Assume that the relevant parameters related to the public are as follows. The interaction and discussion between the public and other agents in the innovation process take opportunity $\operatorname{cost} C_{3}$ and also bring benefits $\left(R_{3}\right)$ to the public. Under the condition of public participation, the responsible government will punish the irresponsible innovation of enterprises and give the public value compensation $K_{2}$. However, when the public does not participate, it cannot obtain interests and any compensation.

Based on the above assumptions, this research starts from the strategic choices of the government, enterprises, and the public to build a tripartite game payoff matrix, as shown in Table 1.

3.2. Multiagent Replicated Dynamics Equation. According to Table 1, the expected payoffs functions of the government's choice of AS and IS strategies are $E_{x}$ and $E_{1-x}$, respectively:

$$
\begin{aligned}
E_{x}= & y z\left(R_{1}-C_{1}-M\right)+y(1-z)\left(R_{1}-C_{1}-M\right) \\
& +(1-y) z\left(T-C_{1}-K_{2}\right)+(1-y)(1-z)(T \\
& \\
E_{1-x}= & y z R_{1}+y(1-z) R_{1}+(1-y) z(-B) \\
& +(1-y)(1-z)(-B),
\end{aligned}
$$$$
+(1-y) z\left(T-C_{1}-K_{2}\right)+(1-y)(1-z)\left(T-C_{1}\right),
$$

Based on equations (1) and (2), from the Malthusian dynamic equation, the government's replication dynamic equation $F(x)$ can be calculated:

$$
\begin{aligned}
F(x) & =\frac{\mathrm{d} x}{\mathrm{~d} t}=x(1-x)\left(E_{x}-E_{1-x}\right) \\
& =x(1-x)\left[T+B-C_{1}-y(M+T+B)-K_{2} z(1-y)\right] .
\end{aligned}
$$

Then, the expected payoffs functions of enterprises' choice of MRI and NMRI strategies are $E_{y}$ and $E_{1-y}$, respectively:

$$
\begin{aligned}
E_{y}= & x z\left(R_{2}-C_{2}+M\right)+x(1-z)\left(R_{2}-C_{2}+M\right) \\
& +(1-x) z\left(R_{2}-C_{2}\right)+(1-x)(1-z)\left(R_{2}-C_{2}\right),
\end{aligned}
$$

$$
\begin{aligned}
E_{1-y}= & x z\left(R_{2}-T\right)+x(1-z)\left(R_{2}-T\right) \\
& +(1-x) z\left(R_{2}-K_{1}\right)+(1-x)(1-z) R_{2} .
\end{aligned}
$$

Based on equations (4) and (5), from the Malthusian dynamic equation, the enterprises' replication dynamic equation $G(y)$ can be calculated:

$$
\begin{aligned}
G(y)= & \frac{\mathrm{d} y}{\mathrm{~d} t}=y(1-y)\left(E_{y}-E_{1-y}\right)=y(1-y)[x(T+M) \\
& \left.+K_{1} z(1-x)-C_{2}\right] .
\end{aligned}
$$

Finally, the expected payoffs functions of the public's choice of PP and NP strategies are $E_{z}$ and $E_{1-z}$, respectively:
TABle 1: Payoff matrix of tripartite collaboration.

\begin{tabular}{lccc}
\hline \multirow{2}{*}{ Strategy selection } & \multicolumn{2}{c}{ Public } \\
& & $\mathrm{PP}(z)$ & $\mathrm{NP}(1-z)$ \\
\hline \multirow{6}{*}{ Enterprises } & $R_{1}-C_{1}-\mathrm{M}$ & $R_{1}-C_{1}-\mathrm{M}$ \\
& MRI $(y)$ & $R_{2}-C_{2}+\mathrm{M}$ & $R_{2}-C_{2}+\mathrm{M}$ \\
Government AS $(x)$ & $R_{3}-C_{3}$ & 0 \\
& Enterprises & $-C_{1}+T-\mathrm{K}_{2}$ & $-C_{1}+T$ \\
& NMRI & $R_{2}-T$ & $R_{2}-T$ \\
& $(1-y)$ & $R_{3}-C_{3}-D+\mathrm{K}_{2}$ & $-D$ \\
\hline \multirow{5}{*}{ Government IS } & Enterprises & $R_{1}$ & $R_{1}$ \\
$(1-x)$ & MRI $(y)$ & $R_{2}-C_{2}$ & $R_{2}-C_{2}$ \\
& Enterprises & $R_{3}-C_{3}$ & 0 \\
& NMRI & $-\mathrm{B}$ & $-\mathrm{B}$ \\
& $(1-y)$ & $R_{2}-\mathrm{K}_{1}$ & $R_{2}$ \\
& & & $-D$ \\
\hline
\end{tabular}

$$
\begin{aligned}
E_{z}= & x y\left(R_{3}-C_{3}\right)+x(1-y)\left(R_{3}-C_{3}-D+K_{2}\right) \\
& +(1-x) y\left(R_{3}-C_{3}\right)+(1-x)(1-y)\left(R_{3}-C_{3}-D+K_{1}\right),
\end{aligned}
$$

$E_{1-z}=x(1-y)(-D)+(1-x)(1-y)(-D)$.

Based on equations (7) and (8), from the Malthusian dynamic equation, the public's replication dynamic equation $H(z)$ can be calculated:

$$
\begin{aligned}
H(z) & =\frac{\mathrm{d} z}{\mathrm{~d} t}=z(1-z)\left(E_{z}-E_{1-z}\right) \\
& =z(1-z)\left[R_{3}-C_{3}+K_{1}(1-x)(1-y)+K_{2} x(1-y)\right] .
\end{aligned}
$$

Consequently, combining equations (3), (6), and (9) can produce a three-dimensional dynamic system including the government, enterprises, and the public:

$$
\left\{\begin{array}{l}
F(x)=x(1-x)\left[T+B-C_{1}-y(M+T+B)-K_{2} z(1-y)\right], \\
G(y)=y(1-y)\left[x(T+M)+K_{1} z(1-x)-C_{2}\right], \\
H(z)=z(1-z)\left[R_{3}-C_{3}+K_{1}(1-x)(1-y)+K_{2} x(1-y)\right] .
\end{array}\right.
$$

\subsection{Equilibrium Point and Multiagent Asymptotic Stability} Analysis. According to equation (10), it is obvious that the three-dimensional dynamic system has 8 equilibrium points, namely, $(0,0,0),(0,1,0),(0,0,1),(0,1,1),(1,0,0),(1,1,0)$, $(1,0,1)$, and $(1,1,1)$, which form the boundary of the domain $\Omega$ of the evolutionary game as $\{(x, y, z) \mid 0 \leq$ $x \leq 1 ; 0 \leq y \leq 1 ; 0 \leq z \leq 1\}$. Also, the three-dimensional dynamic system may have a mixing strategy equilibrium point $E^{*}\left(x^{*}, y^{*}, z^{*}\right)$ that satisfies equation (11). However, when $E^{*} \notin \Omega, E^{*}$ should be rejected. Furthermore, in the tripartite evolutionary game model, the relevant parameters may affect the agent's behavior choices. Therefore, the replicator dynamics equation of each agent can be derived to obtain equation (12): 


$$
\begin{gathered}
\left\{\begin{array}{l}
T+B-C_{1}-y(M+T+B)-K_{2} z(1-y)=0, \\
x(T+M)+K_{1} z(1-x)-C_{2}=0, \\
R_{3}-C_{3}+K_{1}(1-x)(1-y)+K_{2} x(1-y)=0,
\end{array}\right. \\
\left\{\begin{array}{l}
F^{\prime}(x)=(1-2 x)\left[T+B-C_{1}-y(M+T+B)-K_{2} z(1-y)\right], \\
G^{\prime}(y)=(1-2 y)\left[x(T+M)+K_{1} z(1-x)-C_{2}\right], \\
H^{\prime}(z)=(1-2 z)\left[R_{3}-C_{3}+K_{1}(1-x)(1-y)+K_{2} x(1-y)\right] .
\end{array}\right.
\end{gathered}
$$

\subsubsection{Asymptotic Stability Analysis for the Government}

(1) Based on equation (3), if $T+B-C_{1}-y(M+T+$ $B)-K_{2} z(1-y)=0$, there is $F(x) \equiv 0$. At this time, the government's strategic selection will not change over time; that is, the government's strategy is stable.

(2) If $T+B-C_{1}-y(M+T+B)-K_{2} z(1-y)>0$, suppose $F(x)=0$, and $x=0, x=1$ are its two stable solutions. According to $F^{\prime}(x)$ in equation (12), $F^{\prime}(0)>0, F^{\prime}(1)<0$ can be calculated, and then $x=1$ is the equilibrium point. It shows that if the government's penalty $T$ and reputation loss $B$ exceed the sum of the supervision cost $C_{1}$, financial support $M$, and value compensation $K_{2}$, then the active supervision strategy is the evolutionary stable strategy for the government.

(3) If $T+B-C_{1}-y(M+T+B)-K_{2} z(1-y)<0$, at this time, $F^{\prime}(0)<0, F^{\prime}(1)>0$ can be calculated, and then $x=0$ is the equilibrium point. It shows that if the government's penalty $T$ and reputation loss $B$ are lower than the sum of the supervision cost $C_{1}$, financial support $M$, and value compensation $K_{2}$, then the inactive supervision strategy is the evolutionary stable strategy for the government.

\subsubsection{Asymptotic Stability Analysis for Enterprises}

(1) Based on equation (6), if $x(T+M)+K_{1} z(1-x)-$ $C_{2}=0$, there is $G(y) \equiv 0$. At this time, enterprises' strategic selection will not change over time; that is, enterprises' strategy is stable.

(2) If $\quad x(T+M)+K_{1} z(1-x)-C_{2}>0, \quad$ suppose $G(y)=0$, and $y=0, y=1$ are its two stable solutions. According to $G^{\prime}(y)$ in equation (12), $G^{\prime}(0)>0, G^{\prime}(1)<0$ can be calculated, and then $y=$ 1 is the equilibrium point. It shows that if the sum of the punishment $T$, the financial support $M$, and the public compensation $K_{1}$ exceeds its RI investment $C_{2}$, then the making RI strategy is the evolutionary stable strategy for enterprises.

(3) If $x(T+M)+K_{1} z(1-x)-C_{2}<0$, at this time, $G^{\prime}(0)<0, G^{\prime}(1)>0$ can be calculated, and then $y=$ 0 is the equilibrium point. It shows that if the sum of the punishment $T$, the financial support $M$, and the public compensation $K_{1}$ is lower than its RI investment $C_{2}$, then the making irresponsible innovation strategy is the evolutionary stable strategy for enterprises.

\subsubsection{Asymptotic Stability Analysis for the Public}

(1) Based on equation (9), if $R_{3}-C_{3}+K_{1}(1-x)$ $(1-y)+K_{2} x(1-y)=0$, there is $H(z) \equiv 0$. At this time, the public's strategic selection will not change over time; that is, the public's strategy is stable.

(2) If $R_{3}-C_{3}+K_{1}(1-x)(1-y)+K_{2} x(1-y)>0$, suppose $H(z)=0$, and $z=0, z=1$ are its two stable solutions. According to $H^{\prime}(z)$ in equation (12), $H_{\prime}^{\prime}(0)>0, H_{\prime}(1)<0$ can be calculated, and then $z=$ 1 is the equilibrium point. It shows that if the sum of the public's benefits $R_{3}$ and compensation $\left(K_{1}\right.$ and $K_{2}$ ) exceeds its opportunity cost of participation $C_{3}$, then the positive participation strategy is the evolutionary stable strategy for the public.

(3) If $R_{3}-C_{3}+K_{1}(1-x)(1-y)+K_{2} x(1-y)<0$, at this time, $H_{\prime}(0)<0, H_{\prime}(1)>0$ can be calculated, and then $z=0$ is the equilibrium point. It shows that if the sum of the public's benefits $R_{3}$ and compensation $\left(K_{1}\right.$ and $\left.K_{2}\right)$ is lower than its opportunity cost of participation $C_{3}$, then the negative participation strategy is the evolutionary stable strategy for the public.

3.4. Equilibrium Point Stability Analysis. In the previous section, 9 equilibrium points in the three-dimensional dynamic system have been described, but it is uncertain whether these points are the evolutionary stability strategy of the system. According to the research of Wainwright [42] and Lyapunov and Mikhailovich [43], the equilibrium point is asymptotically stable ESS (called sink) only when both strict Nash equilibrium and pure strategy Nash equilibrium are simultaneously satisfied, but $E^{*}$ is a mixed strategy Nash equilibrium, and it is not a sink. Therefore, we only need to analyze the asymptotic stability of the remaining 8 equilibrium points. Then, based on Friedman's research conclusion [44], the local stability of the equilibrium point is analyzed by the system's Jacobian matrix, that is, $\operatorname{det}(J)>0$ and $\operatorname{tr}(J)<0$, thus solving for the system's Jacobian matrix as shown in 


$$
J=\left[\begin{array}{lll}
\frac{\partial F(x)}{\partial x} & \frac{\partial F(x)}{\partial y} & \frac{\partial F(x)}{\partial z} \\
\frac{\partial G(y)}{\partial x} & \frac{\partial G(y)}{\partial y} & \frac{\partial G(y)}{\partial z} \\
\frac{\partial H(z)}{\partial x} & \frac{\partial H(z)}{\partial y} & \frac{\partial H(z)}{\partial z}
\end{array}\right]=\left[\begin{array}{lll}
J_{11} & J_{12} & J_{13} \\
J_{21} & J_{22} & J_{23} \\
J_{31} & J_{32} & J_{33}
\end{array}\right],
$$

where $\quad J_{11}=(1-2 x)\left[T+B-C_{1}-y(M+T+B)-K_{2} z\right.$ $(1-y)] ; J_{12}=x(1-x)\left(K_{2} z-M-T-B\right) ; J_{13}=x(1-x)$ $K_{2}(y-1) ; \quad J_{21}=y(1-y)\left(M+T-K_{1} z\right) ; \quad J_{22}=(1-2 y)$ $\left[x(M+T)+K_{1} z(1-x)-C_{2}\right] ; \quad J_{23}=y(1-y) K_{1}(1-x) ;$ $J_{31}=z(1-z)(1-y)\left(K_{2}-K_{1}\right) ; \quad J_{32}=z(1-z)\left(K_{1} x-K_{2}\right.$ $\left.x-K_{1}\right) ; \quad J_{33}=(1-2 z)\left[R_{3}-C_{3}+K_{1}(1-x)(1-y)+K_{2} x\right.$ $(1-y)]$.

The $\operatorname{det}(J)$ and $\operatorname{tr}(J)$ values of the equilibrium point can be obtained from the above Jacobian matrix and judgment conditions, as shown in Table 2. According to Table 2, the size of $\operatorname{det}(J)$ and $\operatorname{tr}(J)$ is determined by the relevant parameter values, but the existing conditions cannot determine the stability of the 8 equilibrium points; that is, whether there is an equilibrium point that makes the tripartite evolutionary game reach stability is unclear. System dynamics (SD) can analyze the complex dynamic evolution process of the evolutionary game model under the conditions of limited rationality and asymmetric information [45]. Hence, the next section will combine SD simulation tools to construct a multiagent evolutionary game model and analyze the effect of different parameter values on the evolutionary game process.

\section{Numerical Simulation Analysis Based on System Dynamics}

Regarding SD modeling, Sterman [46] pointed out that the simulation model does not lie in how real it is, but in its usefulness, and focuses on revealing the regularity of changes in things. Meanwhile, the correctness of the SD model structure is more important than the parameter value selection, so we should focus on the validity, consistency, and adaptability of the model structure [47]. SD simulation can effectively analyze the feedback behavior of complex systems and the effectiveness of strategies in order to provide practical guidance for designing, formulating, and optimizing management policies [48]. Therefore, this section will construct a multiagent SD model to research the longterm collaborative relationship and behavior strategy evolution of multiagent in responsible innovation, thus providing an experimental platform for studying different influencing factors and making effective decisions.

4.1. Simulation Model Construction. According to the above game analysis and replicator dynamics equations, this study uses Vensim PLE 8.0.9 to establish a multiagent evolutionary game SD model, which includes three subsystems, namely, the government, enterprises, and the public. As shown in
Figure 1, the multiagent evolutionary game SD model is composed of multiple variables, namely, three level variables, three rate variables, nine intermediate variables, and twelve exogenous variables. Specifically, three level variables are used to represent, respectively, the probability of the government choosing AS strategy, probability of enterprises choosing MRI strategy, and probability of the public choosing PP strategy; the change rate of supervision by the government, the change rate of enterprises making responsible innovation, and the change rate of participation by the public are described by three rate variables; and the exogenous variables correspond to the parameters in the payoff matrix of the tripartite collaboration of Table 1. Moreover, in the evolutionary game SD model, the flow rate formula and the functional relation among level variables, rate variables, intermediate variables, and exogenous variables are based mainly on the above multiagent evolutionary game analysis and replicated dynamic equation, namely, equations (1)-(10).

The SD model setting is as follows: INITIAL TIME $=0$, FINAL TIME $=10$, TIME STEP $=0.03125$, Units for Time: Year, and Integration Type: Euler. Meanwhile, according to the case of RI practice $[38,41]$ and related literature value assignment method [49], the initial values of different exogenous variables in the SD model are set as $R_{1}=50, C_{1}=24$, $M=4, T=15, B=13, R_{2}=30, C_{2}=12, K_{1}=4, D=2, K_{2}=3$, $R_{3}=10, C_{3}=8$.

4.2. Model Simulation Analysis. According to the above game equilibrium analysis, it can be seen that an evolutionary equilibrium is bound to be reached among the government, enterprises, and the public, while the reasons, processes, and stability for achieving equilibrium are not clear. Furthermore, because the three-dimensional dynamic system is affected by different factors, which makes the equilibrium state reached in a certain situation quickly broken, therefore, this study uses SD modeling to simulate the dynamic game between the three parties in RI, in order to analyze the multiagent behavior strategy selection and its sensitivity to changes in relevant parameters.

4.2.1. Overall Simulation Analysis of the Model. In the process of RI, when the initial state of the tripartite game among the government, enterprises, and the public is pure strategy, that is, the strategy choices of each agent are divided into 0 and 1, this equilibrium state is unstable and is broken when one or more of multiagents make small changes. Therefore, the equilibrium point $(1,0,0)$ is taken as an example to simulate and analyze the evolution process of multiagent.

As shown in Figure 2, according to the simulation analysis of the equilibrium point $(1,0,0)$, when the government selects the AS strategy, both enterprises and the public play the game with a small probability of strategy selection (that is 0.01 ), whereas, once their strategy mutations can yield higher expected benefits, they adjust the strategy to bring the system to a new equilibrium state. In fact, if enterprises and the public play with a higher 
TABle 2: $\operatorname{det}(J)$ and $\operatorname{tr}(J)$ of the Jacobian matrix.

\begin{tabular}{lcc}
\hline Equilibrium point & $\operatorname{det}(J)$ & $\operatorname{tr}(J)$ \\
\hline$(0,0,0)$ & $-C_{2}\left(T+B-C_{1}\right)\left(R_{3}-C_{3}+K_{1}\right)$ & $T+B-C_{1}-C_{2}+R_{3}-C_{3}+K_{1}$ \\
$(0,1,0)$ & $C_{2}\left(-C_{1}-M\right)\left(R_{3}-C_{3}\right)$ & $-C_{1}-M+C_{2}+R_{3}-C_{3}$ \\
$(0,0,1)$ & $\left(T+B-C_{1}-K_{2}\right)\left(K_{1}-C_{2}\right)\left(C_{3}-R_{3}-K_{1}\right)$ & $T+B-C_{1}-K_{2}-C_{2}+C_{3}-R_{3}$ \\
$(0,1,1)$ & $\left(-C_{1}-M\right)\left(C_{2}-K_{1}\right)\left(C_{3}-R_{3}\right)$ & $-C_{1}-M+C_{2}-K_{1}+C_{3}-R_{3}$ \\
$(1,0,0)$ & $\left(C_{1}-T-B\right)\left(T+M-C_{2}\right)\left(R_{3}-C_{3}+K_{2}\right)$ & $C_{1}-B+M-C_{2}+R_{3}-C_{3}+K_{2}$ \\
$(1,1,0)$ & $\left(C_{1}+M\right)\left(C_{2}-T-M\right)\left(R_{3}-C_{3}\right)$ & $C_{1}+C_{2}-T+R_{3}-C_{3}$ \\
$(1,0,1)$ & $\left(C_{1}-T-B+K_{2}\right)\left(T+M-C_{2}\right)\left(C_{3}-R_{3}-K_{2}\right)$ & $C_{1}-B+M-C_{2}+C_{3}-R_{3}$ \\
$(1,1,1)$ & $\left(C_{1}+M\right)\left(C_{2}-T-M\right)\left(C_{3}-R_{3}\right)$ & $C_{1}+C_{2}-T+C_{3}-R_{3}$ \\
\hline
\end{tabular}

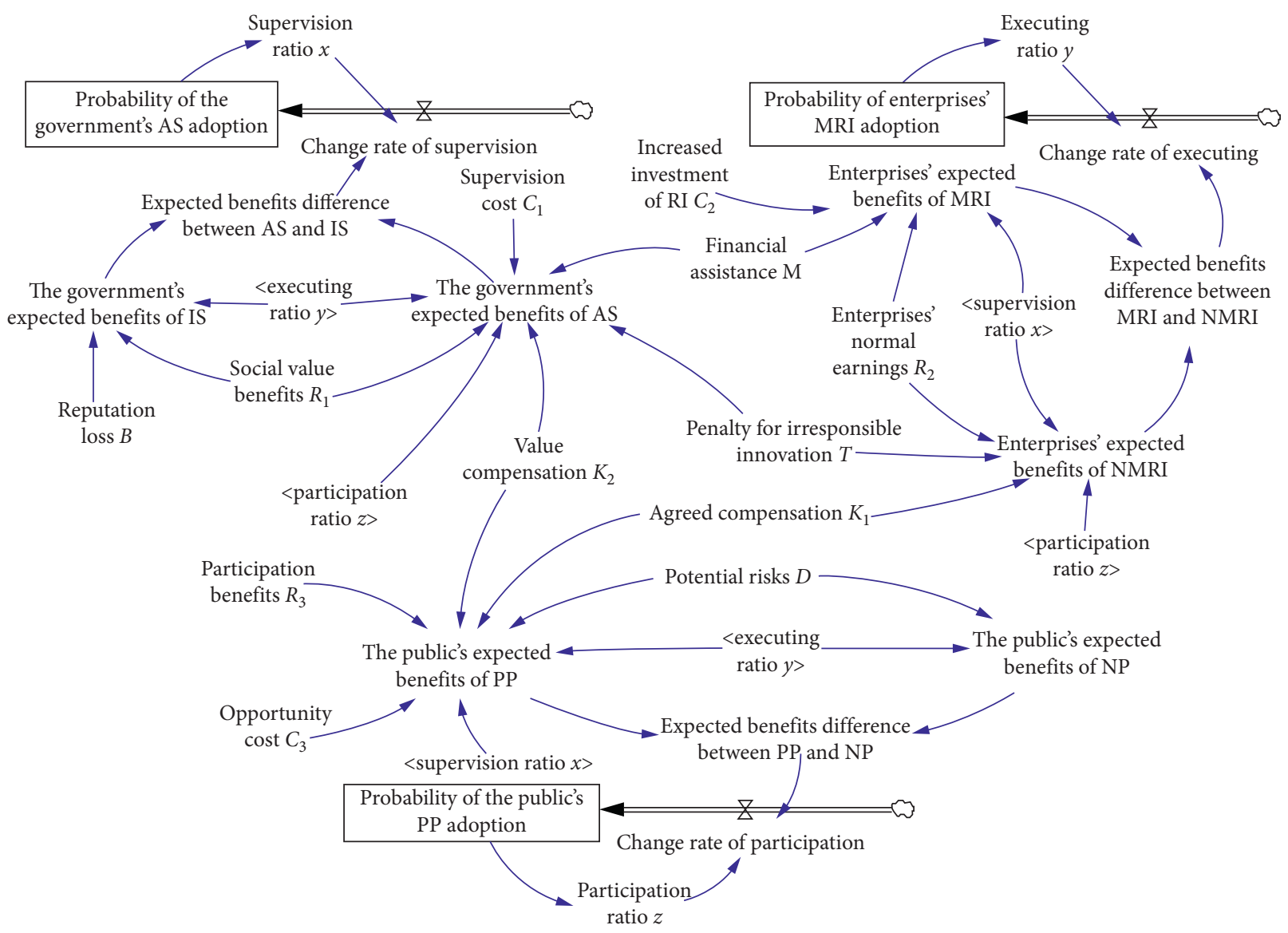

Figure 1: Multiagent evolutionary game SD model.

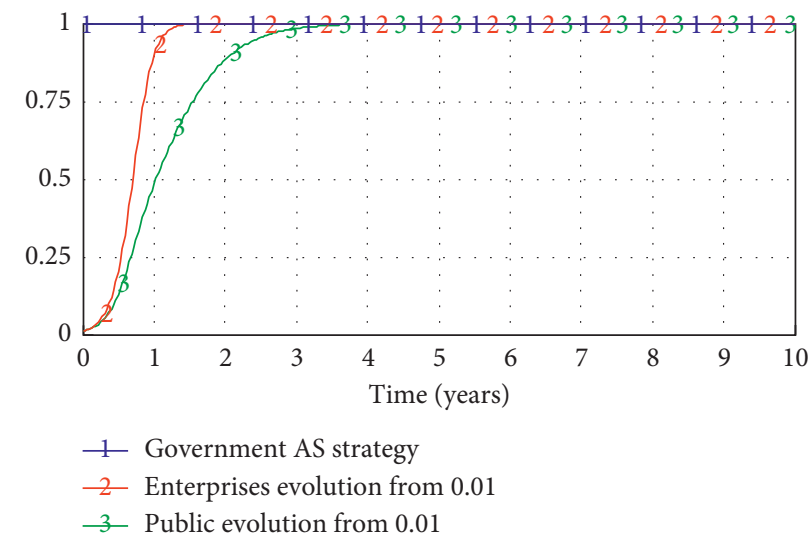

FIGURE 2: The evolution process of $y$ and $z$ starting from 0.01 . 
probability, the time for making strategy selection is shorter and the range of change is larger, and eventually the system will reach a new equilibrium state.

The external pressure from public participation in RI forced the government and enterprises to act to understand and respond to societal needs and values. Simulating the stability of other equilibrium points also verifies that public participation is its optimal choice; namely, when the public makes strategic choices with a small probability mutation, they will eventually reach an equilibrium state of 1 . As shown in Figure 3, when the public is always actively participating in the process of RI, if the government chooses the AS strategy, no matter which strategy enterprises choose to mutate, its final strategy choice will reach an equilibrium state of 1; that is, enterprises make RI, which is consistent with the simulation results of the equilibrium points $(1,0,1)$ and $(1,1,1)$. However, once the government chooses the IS strategy, the final strategic choice of enterprises will reach an equilibrium state of 0 (see Figure 4); that is, enterprises make irresponsible innovation, which corresponds to the simulation results at the equilibrium points $(0,0,1)$ and $(0,1,1)$.

Similarly, under the conditions of public positive participation, if enterprises select the MRI strategy, regardless of which strategy the government chooses to play, it will ultimately choose the IS strategy. Over time, the lax state of the government will drive enterprises to select the NMRI strategy. At this time, no matter which strategy the government chooses to play, it will eventually choose the AS strategy to break the initial equilibrium state of $(0,0,1)$. Through the repeated evolutionary game, the evolution of each agent strategy is ultimately stabilized in the equilibrium state of $(1,1,1)$.

4.2.2. Simulation Analysis of the Government Strategy Selection. According to the local stability analysis of the equilibrium point in Table 2, the stability of the equilibrium point depends on the size of the relevant game parameters, that is, the value of exogenous variables in the SD game model. The following is still taking the strategy combination $(1,0,0)$ as an example to analyze the sensitivity of the government strategy selection to the change of exogenous variables.

Assume that the government's initial strategy choice is inactive supervision and the evolutionary game is mutated from 0 to 0.1 . It can be seen from the dynamic simulation that the government's strategic choices are primarily affected by two exogenous variables, namely, supervision cost $C_{1}$ and penalty $T$ for irresponsible innovation to enterprises. As shown in Figures 5 and 6, when the government's strategy selection begins to evolve from the initial supervision cost, the response time for strategy selection becomes shorter as the cost decreases, and the equilibrium state of 1 is reached faster; otherwise, if the cost increases beyond the government's tolerance, its strategy choice evolves to an "inactive supervision" state of 0 . Meanwhile, the higher the penalty threshold for enterprises, the greater the variability and probability that the government chooses the AS strategy. Moreover, comparing Figures 5 and 6, it can be seen that the

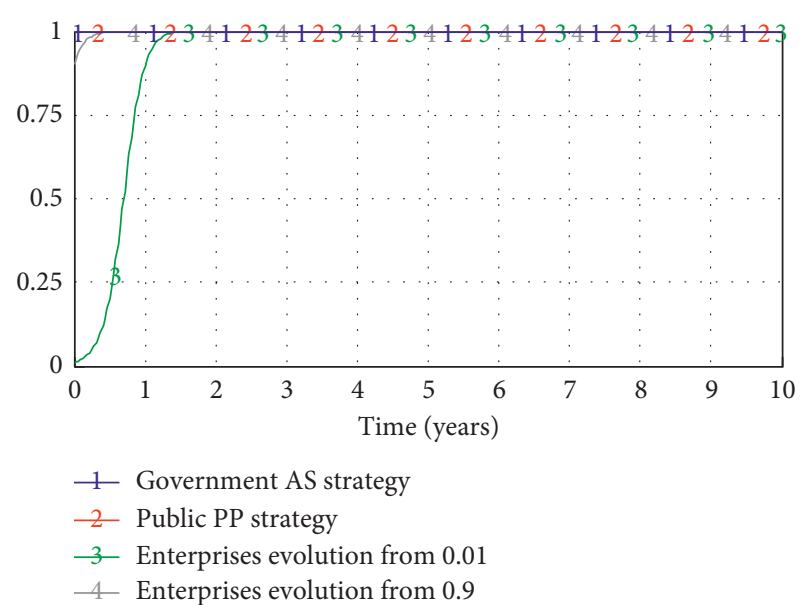

FIgURE 3: The evolutionary process of enterprises under active supervision strategy.

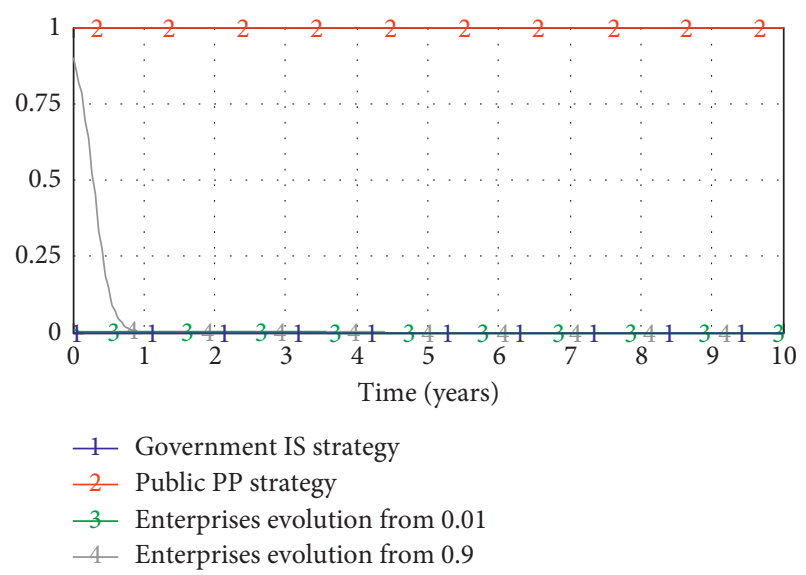

FIgURE 4: The evolutionary process of enterprises under active supervision strategy.

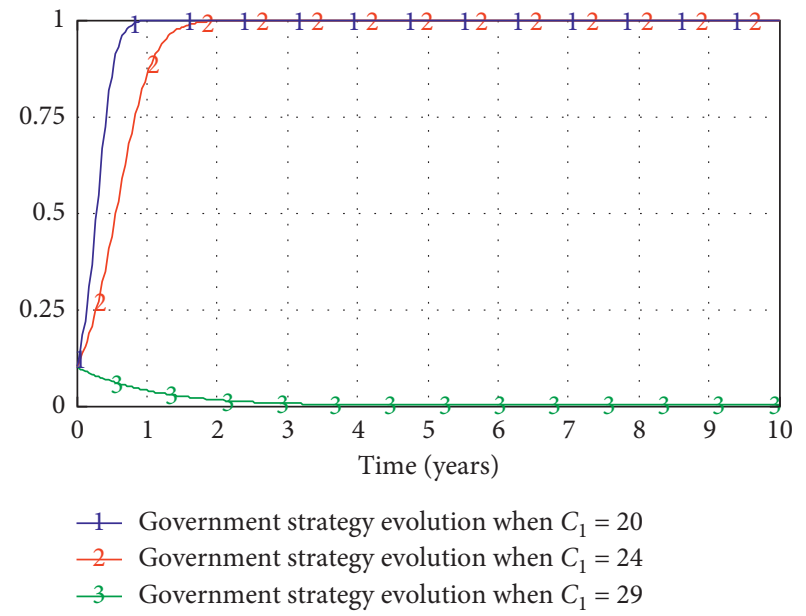

FIgURE 5: The impact of $C_{1}$ on the government strategy selection.

greater the probability that the government chooses AS strategy, that is, the higher the government's supervision for enterprises, the greater the penalty for enterprises' 


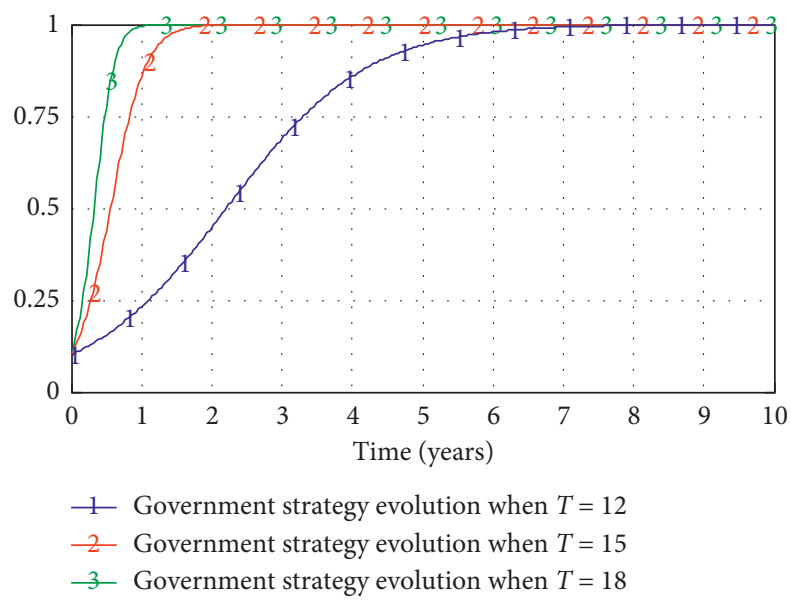

FIgURE 6: The impact of $T$ on government strategy selection.

irresponsible innovation, which compensates for the higher cost of making an AS strategy faster.

4.2.3. Simulation Analysis of Enterprises Strategy Selection. According to the local stability analysis of the equilibrium point in Table 2 , the strategy combination $(1,0,0)$ is taken as an example to analyze the sensitivity of enterprises' strategy selection to the change of exogenous variables. Further analysis found that enterprises' strategic choices were mainly influenced by exogenous variables such as the increased $\mathrm{R} \& \mathrm{D}$ investment $C_{2}$ and penalty $T$.

As shown in Figure 7, enterprises start a game with a probability of 0.1 ; when their $\mathrm{R} \& \mathrm{D}$ costs are lower and penalties are higher, their response time to choose an MRI strategy is shorter and reaches an equilibrium of 1 faster. As the cost increases to the equivalent of penalty, the enterprises' response for strategy selection becomes slower, and once the cost is too high or even exceeds the penalty, enterprises may mutate to an equilibrium of 0 ; that is, enterprises would rather choose to accept punishment than make RI. This also indicates that a stable difference between $\mathrm{C}_{2}$ and $T$ must be maintained; once a variable is too high or low, this will affect the strategic choice of enterprises to achieve a stable state. This is also true in reality, where the intensity of the government penalty may affect the threshold for enterprises to bear punishment, and once the threshold is too high, it will make enterprises reduce their sensitivity to punishment and lose the motivation effect.

4.2.4. Simulation Analysis of the Public Strategy Selection. According to the local stability analysis of the equilibrium point in Table 2, the strategy combination $(1,0,0)$ is taken as an example to analyze the sensitivity of the public's strategy selection to the change of exogenous variables. Further analysis found that the public's strategic choices were mainly influenced by exogenous variables such as opportunity cost $C_{3}$, participation benefits $R_{3}$, and value compensation $K_{2}$.

As shown in Figure 8, when the public starts mutation with a probability of 0.1 to make an evolutionary game, it is found that three exogenous variables increase or decrease separately;

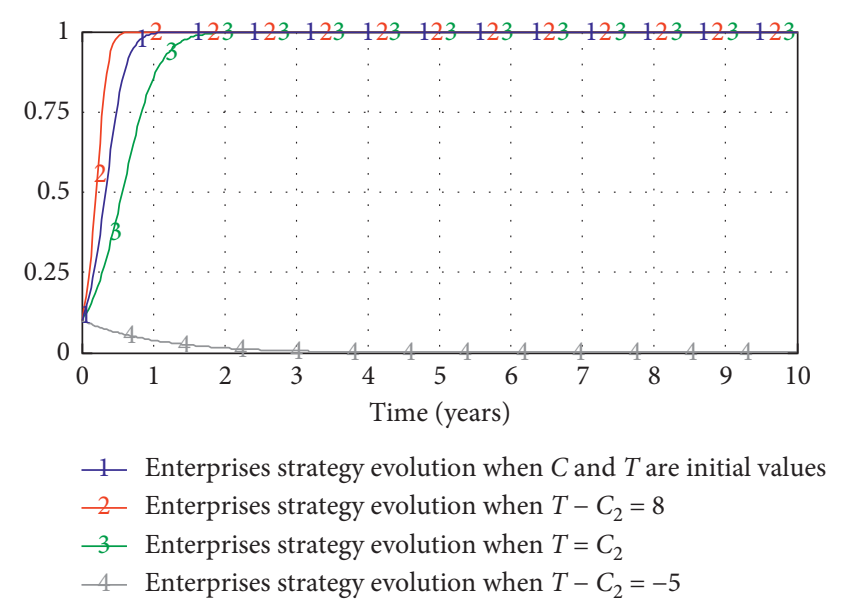

FIgURE 7: The impact of $C_{2}$ and $T$ on enterprises strategy selection.

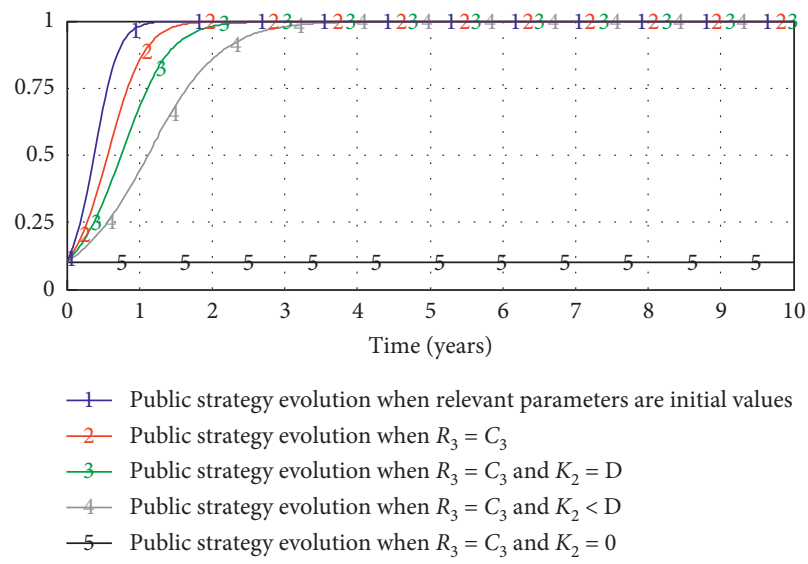

FIgUre 8: The impact of $R_{3}, C_{3}$, and $K_{2}$ on the public strategy selection.

namely, $R_{3}$ and $K_{2}$ increase, $C_{3}$ decreases, the public chooses the PP strategy with shorter reaction time and greater probability, and the trend of change is similar to that of the government and enterprises, with an s-type curve evolution. Specifically, the public responds faster to making strategic choices when each variable is the initial value, while the government's value compensation $\mathrm{K}_{2}$ significantly affects the public's strategy selection as the cost of participation increases. Once this kind of negative external value compensation is reduced or is even 0 , the public will reduce the probability of strategy choice because the risks suffered cannot be compensated for; but excessively higher value compensation will increase the government's financial burden and force it to change its strategic choices. Therefore, in the process of RI, the expected benefits of public participation and government compensation are important factors influencing the choice of strategy for the public, and the government should pay attention to the "bottom line" of public participation and set a reasonable amount of compensation.

\section{Conclusions}

In the process of RI, a stable collaborative relationship is a fundamental prerequisite for achieving responsible 
governance in scientific and technological innovation. In this paper, the evolutionary game method is used to construct a behavioral strategy game model of multiagent participation in RI and finally draw some significant conclusions by system dynamics simulation.

First, the strategies of tripartite eventually converged to the best equilibrium state of the government's active supervision, enterprises making responsible innovation, and the public's positive participation. Second, the active participation of the public promotes the game to reach a stable state more quickly, and enterprises' behavior strategies are more susceptible to government actions. Third, supervision cost, penalty amount, and value compensation are the most important factors that affect the change of the corresponding agent's behavior strategy, and the final strategic stability of tripartite is influenced by multiple exogenous variables.

Given the above research results, the government, first of all, should play a leading role and establish an institutional system that matches responsible innovation. Then, it should establish a linkage mechanism between reward and penalty and setting a reasonable threshold for penalties. Third, the government should construct a sound public decisionmaking participation mechanism, which can improve the rationality of related innovation decisions.

This research contends with several limitations. First, for the convenience of analysis, all multiagent and influencing factors are not considered. Second is the lack of actual data of exogenous variables due to conditional constraints; we only set the values of exogenous variables for the evolutionary game by referring to the case of responsible innovation practice and related research assignment method. Therefore, in future research, we will combine practice investigation by adding real data and more influencing factors and agents into the model.

\section{Data Availability}

The simulation data used to support the findings of this study are included within the article.

\section{Conflicts of Interest}

The authors declare that there are no conflicts of interest regarding the publication of this paper.

\section{Acknowledgments}

This work was supported by the Ministry of Education Humanities and Social Sciences Planning Foundation of China (Grant no. 19YJA790028), National Natural Science Foundation of China (Grant no. 71502101), and Shanghai Philosophy and Social Science Foundation (Grant no. 2019EGL017).

\section{References}

[1] G. George, J. Howard-Grenville, A. Joshi, and L. Tihanyi, "Understanding and tackling societal grand challenges through management research," Academy of Management Journal, vol. 59, no. 6, pp. 1880-1895, 2016.
[2] B. Godin, Innovation Contested: The Idea of Innovation over the Centuries, Routledge, Abingdon, UK, 2015.

[3] J. Stilgoe, R. Owen, and P. Macnaghten, "Developing a framework for responsible innovation," Research Policy, vol. 42, no. 9, pp. 1568-1580, 2013.

[4] B. E. Ribeiro, R. D. J. Smith, and K. Millar, "A mobilising concept? unpacking academic representations of responsible research and innovation," Science and Engineering Ethics, vol. 23, no. 1, pp. 81-103, 2017.

[5] S. Khavul and G. D. Bruton, "Harnessing innovation for change: sustainability and poverty in developing countries," Journal of Management Studies, vol. 50, no. 2, pp. 285-306, 2013.

[6] L. M. D. Silva, C. C. Bitencourt, K. Faccin, and T. Iakovleva, "The role of stakeholders in the context of responsible innovation: a meta-synthesis," Sustainability, vol. 11, no. 6, p. 1766, 2019.

[7] R. Von Schomberg, "A vision of responsible research and innovation," in Responsible Innovation, J. B. R. Owen and M. Heintz, Eds., John Wiley \& Sons, Chichester, UK, pp. 51-74, 2013.

[8] E. Fisher and A. Rip, "Responsible innovation: multi-level dynamics and soft intervention practices," in Responsible Innovation, R. Owen, J. Bessant, and M. Heintz, Eds., pp. 165-183, John Wiley \& Sons, Chichester, UK, 2013.

[9] V. Blok and P. Lemmens, "The emerging concept of responsible innovation: three reasons why it is questionable and calls for a radical transformation of the concept of innovation," in Responsible Innovation 2, B.-J. Koops, I. Oosterlaken, H. Romijn, T. Swierstra, and J. V. D. Hoven, Eds., Springer, Cham, Switzerland, 2015.

[10] T. Brand and V. Blok, "Responsible innovation in business: a critical reflection on deliberative engagement as a central governance mechanism," Journal of Responsible Innovation, vol. 6, no. 1, pp. 4-24, 2019.

[11] A. Genus and M. Iskandarova, "Responsible innovation: its institutionalisation and a critique," Technological Forecasting and Social Change, vol. 128, pp. 1-19, 2018.

[12] R. Owen, S. Jack, P. Macnaghten, M. Gorman, E. Fisher, and D. Guston, "A framework for responsible innovation," in Responsible Innovation, R. Owen, J. Bessant, and M. Heintz, Eds., John Wiley \& Sons, Chichester, UK, pp. 27-50, 2013.

[13] K. Jarmai and H. Vogel-Pöschl, "Meaningful collaboration for responsible innovation," Journal of Responsible Innovation, vol. 7, no. 1, pp. 138-143, 2020.

[14] D. Arenas, P. Sanchez, M. Murphy, and M. Murphy, "Different paths to collaboration between businesses and civil society and the role of third parties," Journal of Business Ethics, vol. 115, no. 4, pp. 723-739, 2013.

[15] R. Von Schomberg, "Prospects for technology assessment in a framework of responsible research and innovation," in Technikfolgen Abschätzen Lehren, M. Dusseldorp and R. Beecroft, Eds., Springer, Wiesbaden, Germany, pp. 39-61, 2012.

[16] R. Lubberink, V. Blok, J. Van Ophem, and O. Omta, "Lessons for responsible innovation in the business context: a systematic literature review of responsible, social and sustainable innovation practices," Sustainability, vol. 9, no. 5, p. 721, 2017.

[17] A. Pyka, "Avoiding evolutionary inefficiencies in innovation networks," Prometheus, vol. 32, no. 3, pp. 265-279, 2014.

[18] M. P. Schlaile, M. Mueller, M. Schramm, and A. Pyka, "Evolutionary economics, responsible innovation and demand: making a case for the role of consumers," Philosophy of Management, vol. 17, no. 1, pp. 7-39, 2018. 
[19] J. Bessant, "Innovation in the twenty-first century," in Responsible Innovation: Managing the Responsible Emergence of Science and Innovation in Society, R. Owen, J. Bessant, and M. Heintz, Eds., pp. 1-25, John Wiley \& Sons, Chichester, UK, 2013.

[20] H. Zwart, L. Landeweerd, and A. Van Rooij, “Adapt or perish? assessing the recent shift in the European research funding arena from "elsa" to "rri"," Life Sciences, Society and Policy, vol. 10, no. 11, pp. 1-19, 2014.

[21] P. Macnaghten, R. Owen, J. Stilgoe et al., "Responsible innovation across borders: tensions, paradoxes and possibilities," Journal of Responsible Innovation, vol. 1, no. 2, pp. 191-199, 2014.

[22] M. Burget, E. Bardone, and M. Pedaste, "Definitions and conceptual dimensions of responsible research and innovation: a literature review," Science and Engineering Ethics, vol. 23, no. 1, pp. 1-19, 2017.

[23] R. Von Schomberg, Towards Responsible Research and Innovation in the Information and Communication Technologies and Security Technologies Fields, European Commission Services, Brussels, Belgium, 2011.

[24] S. R. Davies and M. Horst, "Responsible innovation in the US, UK and Denmark: governance landscapes," in Responsible Innovation 2, B.-J. Koops, I. Oosterlaken, H. Romijn, T. Swierstra, and J. V. D. Hoven, Eds., vol. 37, Cham, Switzerland, Springer, 2015.

[25] V. Blok, L. Hoffmans, and E. F. M. Wubben, "Stakeholder engagement for responsible innovation in the private sector: critical issues and management practices," Journal on Chain and Network Science, vol. 15, no. 2, pp. 147-164, 2015.

[26] L. Mei and J. Chen, "Responsible innovation: origin, attribution and theoretical framework," Management World, vol. 8, pp. 39-57, 2015, in Chinese.

[27] N. M. Dahan, J. P. Doh, and J. D. Raelin, "Pivoting the role of government in the business and society interface: a stakeholder perspective," Journal of Business Ethics, vol. 131, no. 3, pp. 665-680, 2015.

[28] N. Thomas and H. Rogers, "Responsible innovation in supply chains: insights from a car development perspective," in Proceedings of the $4^{\text {th }}$ International Conference LDIC, Bremen, Germany, 2016.

[29] W.-M. Hur, H. Kim, and J. Woo, "How csr leads to corporate brand equity: mediating mechanisms of corporate brand credibility and reputation," Journal of Business Ethics, vol. 125, no. 1, pp. 75-86, 2014.

[30] A. Gurzawska, "Towards responsible and sustainable supply chains-innovation, multi-stakeholder approach and governance," Philosophy of Management, 2019.

[31] I. Bouzguenda, C. Alalouch, and N. Fava, "Examining digital participatory planning: maturity assessment in a small Dutch city," Journal of Cleaner Production, vol. 264, Article ID 121706, 2020.

[32] A. Gurzawska, M. Mäkinen, and P. Brey, "Implementation of responsible research and innovation (rri) practices in industry: providing the right incentives," Sustainability, vol. 9, no. 10, p. 1759, 2017.

[33] L. Samuelson, "Evolution and game theory," Journal of Economic Perspectives, vol. 16, no. 2, pp. 47-66, 2002.

[34] R. Zhao, X. Zhou, J. Han, and C. Liu, "For the sustainable performance of the carbon reduction labeling policies under an evolutionary game simulation," Technological Forecasting and Social Change, vol. 112, pp. 262-274, 2016.

[35] X. Liu, Z. Fang, N. Zhang, K. Liu, and Z. Jingfeng, "An evolutionary game model and its numerical simulation for collaborative innovation of multiple agents in carbon fiber industry in China," Sustainable Computing: Informatics and Systems, vol. 24, p. 100350, 2019.

[36] B. Guo and J. Li, "Research on the evolution of participants collaboration mechanism in ppp model based on computer simulation: based on the old community renovation project," The Journal of Supercomputing, vol. 76, no. 4, pp. 2417-2434, 2020.

[37] Y. Chen, Z. Hu, Q. Liu, and S. Chen, "Evolutionary game analysis of tripartite cooperation strategy under mixed development environment of cascade hydropower stations," Water Resources Management, vol. 34, no. 6, pp. 1951-1970, 2020.

[38] W. Ravesteijn, Y. Liu, and P. Yan, "Responsible innovation in port development: the rotterdam maasvlakte 2 and the dalian dayao bay extension projects," Water Science and Technology, vol. 72, no. 5, pp. 665-677, 2015.

[39] L. Song and W. Ravesteijn, "Responsible port innovation in China: the case of the yangshan port extension project," International Journal of Critical Infrastructures, vol. 11, no. 4, pp. 297-315, 2015.

[40] J. Voeten, J. D. Haan, G. D. Groot, and N. Roome, "Understanding responsible innovation in small producers' clusters in vietnam through actor-network theory," The European Journal of Development Research, vol. 27, no. 2, pp. 289-307, 2015.

[41] W. Ravesteijn, J. He, and C. Chen, "Responsible innovation and stakeholder management in infrastructures: the nansha port railway project," Ocean \& Coastal Management, vol. 100, pp. 1-9, 2014.

[42] J. Wainwright, "A dynamical systems approach to bianchi cosmologies: orthogonal models of class a," Classical and Quantum Gravity, vol. 6, no. 10, pp. 1409-1431, 1989.

[43] A. M. Lyapunov and A. Mikhailovich, "The general problem of the stability of motion," International Journal of Control, vol. 55, no. 3, pp. 531-534, 1992.

[44] D. Friedman, "Evolutionary games in economics," Econometrica, vol. 59, no. 3, pp. 637-666, 1991.

[45] D.-H. Kim, D. H. Kim, and D. H. Kimb, "A system dynamics model for a mixed-strategy game between police and driver," System Dynamics Review, vol. 13, no. 1, pp. 33-52, 1997.

[46] J. Sterman, Business Dynamics: Systems Thinking and Modeling for a Complex World, McGraw-Hill Education, Boston, MA, USA, 2000.

[47] D. D. Wu, X. Kefan, L. Hua, Z. Shi, and D. L. Olson, "Modeling technological innovation risks of an entrepreneurial team using system dynamics: an agent-based perspective," Technological Forecasting and Social Change, vol. 77, no. 6, pp. 857-869, 2010.

[48] M. You, S. Li, D. Li, Q. Cao, and F. Xu, "Evolutionary game analysis of coal-mine enterprise internal safety inspection system in China based on system dynamics," Resources Policy, vol. 67, p. 101673, 2020.

[49] Q. Liu, X. Li, and X. Meng, "Effectiveness research on the multi-player evolutionary game of coal-mine safety regulation in China based on system dynamics," Safety Science, vol. 111, pp. 224-233, 2019. 